\title{
Nitric oxide release from the S-nitrosothiol zinc phthalocyanine complex by flash photolysis
}

J.C.G. Rotta,

C.N. Lunardi and

A.C. Tedesco
Departamento de Química, Faculdade de Filosofia,

Ciências e Letras de Ribeirão Preto, Universidade de São Paulo, Ribeirão Preto, SP, Brasil

\author{
Correspondence \\ A.C. Tedesco \\ Departamento de Química \\ FFCLRP, USP \\ Av. Bandeirantes, 3900 \\ 14040-901 Ribeirão Preto, SP \\ Brasil \\ Fax: +55-16-633-8151 \\ E-mail: tedesco@ffclrp.usp.br \\ Research supported by FAPESP \\ (Nos. 99/01394-3 and 00/00431-1).
}

Received April 11, 2002 Accepted January 15, 2003

\begin{abstract}
The photogeneration of nitric oxide (NO) using laser flash photolysis was investigated for S-nitroso-glutathione (GSNO) and S-nitroso- $\mathrm{N}$ acetylcysteine (NacySNO) at $\mathrm{pH} 6.4(\mathrm{PBS} / \mathrm{HCl})$ and 7.4 (PBS). Irradiation of S-nitrosothiol with light $(\lambda=355 \mathrm{~nm}$ followed by absorption spectroscopy) resulted in the homolytic decomposition of NacySNO and GSNO to generate radicals (GS• and NacyS $S^{\bullet}$ ) and NO. The release of NO from donor compounds measured with an ISONometer apparatus was larger at $\mathrm{pH} 7.4$ than $\mathrm{pH}$ 6.4. NacySNO was also incorporated into dipalmitoyl-phosphatidylcholine liposomes in the presence and absence of zinc phthalocyanine (ZnPC), a wellknown photosensitizer useful for photodynamic therapy. Liposomes are usually used as carriers for hydrophobic compounds such as ZnPC. Inclusion of $\mathrm{ZnPC}$ resulted in a decrease in NO liberation in liposomal medium. However, there was a synergistic action of both photosensitizers and S-nitrosothiols resulting in the formation of other reactive species such as peroxynitrite, which is a potent oxidizing agent. These data show that $\mathrm{NO}$ release depends on $\mathrm{pH}$ and the medium, as well as on the laser energy applied to the system. Changes in the absorption

spectrum were monitored as a function of light exposure.
\end{abstract}

\section{Introduction}

S-nitrosothiols (thionitriles), compounds with the generic structure RSNO, have become important recently because of a series of demonstrations of the in vivo synthesis of nitric oxide (NO) and its control of a range of physiological functions $(1,2)$. RSNO are potent antiplatelet agents and vasodilators (3). Both of these functions are usually attributed to NO release and there is interest in the potential of S-nitrosothiols as in vivo carriers
Key words

- S-nitrosothiols

- Nitric oxide

- Zinc phthalocyanine

- Liposomes

- Photodynamic therapy

...................... of NO to target areas such as tumors where NO could act as a phototoxic agent (4).

$\mathrm{NO}$ is an endogenous mediator of numerous physiological processes and the precise biological effects of NO production depend largely upon the rate and local of NO generation. NO can act both as a biological messenger and as a tumoricidal cytotoxin (5). The participation of NO in the tumoricidal activity of macrophages was one the first roles reported for this molecule (6). Though NO may be an important factor in host defense 
against cancer, other reports suggest that $\mathrm{NO}$ promotes tumor growth (7). Thus, the determination of the mechanism of NO utilization requires an understanding of factors such as its rate of release, local concentration, and intracellular localization (7).

S-nitrosothiols have been described as reservoirs of $\mathrm{NO}$ in vivo due to their higher stability in comparison with $\mathrm{NO}$, which has a short half-life in biological systems. The liberation of NO is promoted by chemical means, by light and by a combination of the two (photosensitization protocols) (6). The mechanism of the photochemical release of NO from S-nitrosothiol has been determined using laser flash photolysis (4).

Photodynamic sensitizers such as zinc phthalocyanine (ZnPC) produce active oxygen species by type I and type II mechanisms (8). Triplet sensitizers can undergo their primary reactions with molecules in their vicinity by an electron (or $\mathrm{H}$ atom) transfer process (termed a type I, i.e., a radical or redox reaction), or by an energy transfer reaction (termed a type II process). Localized production of singlet oxygen and superoxide radicals $\left(\mathrm{O}_{2}{ }^{-}\right)$as a cytotoxic and antiviral process has been achieved in photodynamic therapy, which involves the use of photosensitization combined with light (9). Upon activation, $\mathrm{ZnPC}$ generates reactive oxygen species (singlet oxygen and free radicals such as ${ }^{\bullet} \mathrm{OH}, \mathrm{HO}_{2} \cdot$ and $\mathrm{O}_{2}{ }^{--}$) which damage membranes, DNA and other cell structures (9). All these processes are summarized in Figure 1.

The use of photosensitizing drugs associated with different vehicles, such as liposomes, has received strong interest within the field of tumor photodynamic therapy $(9,10)$. Since NO exhibits tumoricidal and antiviral activity, it may be possible to exploit photosensitized NO in clinical photodynamic therapy.

In the present study we show that the decomposition of S-nitrosothiols by laser flash photolysis is $\mathrm{pH}$ and medium depend- ent. The main objective of the present study was to report the synergistic effect of both species $\left(\mathrm{NO}, \mathrm{O}_{2}{ }^{--}\right)$produced in the medium and capable of producing $\mathrm{ONOO}^{-}$. This is of biological interest since these are active species in photodynamic therapy.

\section{Material and Methods}

\section{Reagents}

Sodium nitrite $\left(\mathrm{NaNO}_{2}\right)$, sodium hydroxide $(\mathrm{NaOH})$ and dipalmitoyl-phosphatidyl choline (DPPC) were purchased from Sigma (St. Louis, MO, USA), and ZnPC was purchased from Aldrich (Milwaukee, WI, USA). The buffers used were $10 \mathrm{mM}$ sodium phosphate buffer (PBS), pH 7.4 (Sigma), and 10 $\mathrm{mM}$ PBS/ $\mathrm{HCl}, \mathrm{pH}$ 6.4, containing $0.1 \mathrm{M}$ hydrochloric acid $(\mathrm{HCl})$ (Merck, Darmstadt, Germany).

\section{Synthesis of GSNO and NacySNO}

S-nitrosothiols were synthesized by the method of Ceron et al. (3). They were prepared by reacting equimolar amounts of $\mathrm{NaNO}_{2}$ and the corresponding thiol (glutathione or $\mathrm{N}$-acetylcysteine) in aqueous solution. The solutions were adjusted to $\mathrm{pH} 2.0$ with $6 \mathrm{M} \mathrm{HCl}$ and incubated at $37^{\circ} \mathrm{C}$ for 5 min, by which time a characteristic red/orange color was developed. The samples were neutralized to $\mathrm{pH} 7.0$ with $\mathrm{NaOH}$ and then lyophilized.

The structure of RSNO was confirmed by proton nuclear magnetic resonance and their concentrations were determined spectrophotometrically at $330 \mathrm{~nm}$ based on extinction coefficients $\left(\varepsilon_{330}\right)$ of 767 for Snitroso-glutathione (GSNO) and 727 for Snitroso- $N$-acetylcysteine (NacySNO) $(2,4)$.

\section{Preparation of unilamellar vesicles}

The liposome dispersion was prepared by the injection method of Kremer et al. (11). 
This procedure allows the preparation of unilamellar vesicles of predetermined size by the injection of ethanol containing different concentrations of phospholipid into an aqueous-buffered solution. The injection containing 9.21 mM DPPC solution in absolute ethanol was performed at $55^{\circ} \mathrm{C}$ with magnetic stirring at a speed of $1 \mu \mathrm{l} / \mathrm{s}$. The system was then allowed to cool to room temperature and was passed through a $0.454-$ $\mu \mathrm{m}$ Millipore filter. The organic solvents were eliminated by dialyzing the aqueous liposome dispersion at $4^{\circ} \mathrm{C}$ against $250 \mathrm{ml}$ of phosphate buffer for $6 \mathrm{~h}$. The RSNO $(2 \mathrm{mM})$ were incorporated into the liposomes by adding the amount of RSNO salt needed to reach a final concentration of $2 \mathrm{mM}$, and subsequently stirring for $15 \mathrm{~min}$. The $\mathrm{ZnPC}$ concentration of $5 \mu \mathrm{M}$ in the liposomes was obtained by adding suitable volumes of a stock $(1 \mathrm{mM})$ pyridine solution of the sensitizer to the ethanol DPPC solution, with subsequent injection into the buffer solution.

\section{Measurement of nitric oxide}

The concentration of NO released by RSNO was measured with an ISO-NO amperometric sensor (World Precision Instrument, Inc., Sarasota, FL, USA) with a sensitivity range of $1 \mathrm{nM}$ to $20 \mu \mathrm{M} \mathrm{NO}$ and a detection limit of $1 \mathrm{nM}$. This sensor detects NO directly by amperometric techniques. The ISO-NO sensor was calibrated daily when in use by a quantitative NO generation reaction according to the procedure described in the Instruction Manual of ISO-NO (12). The analog signal output from ISO-NO was recorded with a PC-based data acquisition system (DUO 18, World Precision Instrument). All experiments were carried out at $37^{\circ} \mathrm{C}$.

\section{Laser flash photolysis experiments}

All solutions were freshly prepared and protected against light using aluminum foil until the beginning of irradiation to prevent any prestimulated decomposition. RSNO (2 $\mathrm{mM}$ ) solutions were placed in a 1-cm quartz cuvette with constant stirring. Excitation was provided by a frequency-triplet, mode locked $\mathrm{Nd}$ :YAG laser at $355 \mathrm{~nm}$ (Continuum, Santa Clara, CA, USA). The focused incident beam (8-ns pulse duration) was set at 10 to $50 \mathrm{~mJ}$ per pulse with an average of 10 shots per irradiation cycle. The ground-state absorption spectrum was determined using a Hitachi U-300 spectrophotometer. All experiments involved aerated buffered (PBS, $\mathrm{pH}$ 7.4, and $\mathrm{PBS} / \mathrm{HCl}, \mathrm{pH}$ 6.4) liposome solutions of $2.0 \mathrm{mM}$ RSNO.

\section{Results and Discussion}

The UV-visible spectra of RSNO showed two bands, one in the range of 330-350 nm $\left(\varepsilon \sim 10^{3} \mathrm{M}^{-1} \mathrm{~cm}^{-1}, \mathrm{n}_{0} \rightarrow \pi^{*}\right)$ and the other in the 550-600 nm region $\left(\varepsilon \sim 20 \mathrm{M}^{-1} \mathrm{~cm}^{-1}, \mathrm{n}_{\mathrm{N}}\right.$ $\rightarrow \pi^{*}$ ) (Figure 2). These absorbances are
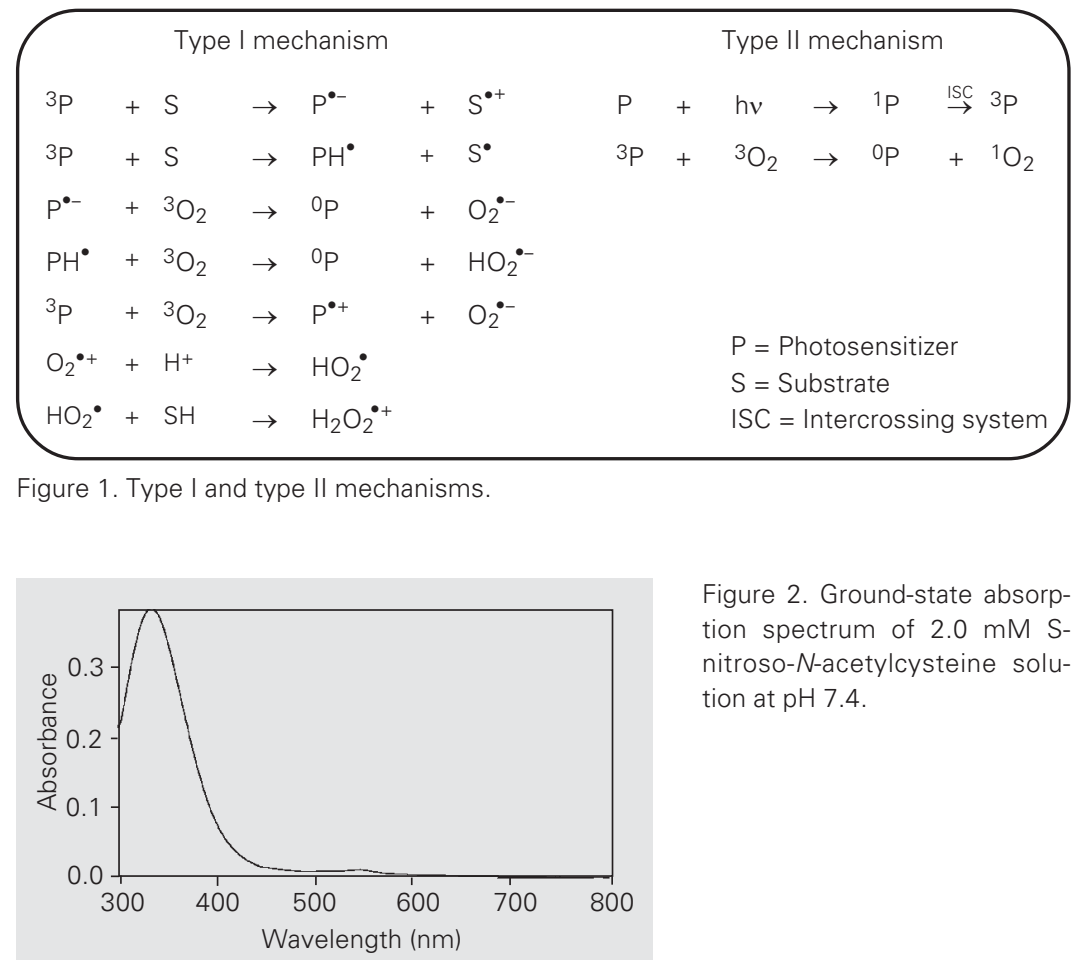

Figure 2. Ground-state absorption spectrum of $2.0 \mathrm{mM} \mathrm{S}$ nitroso- $\mathrm{N}$-acetylcysteine solution at $\mathrm{pH}$ 7.4. 
used to monitor RSNO decomposition (13).

The homolytic fission of the S-N bond in RSNO occurs photochemically by irradiation at either absorption maximum band (340 or $545 \mathrm{~nm}$ ). A convenient way of exciting ground state GSNO and NacySNO has been laser excitation at $355 \mathrm{~nm}$ in view of the higher absorption coefficient of both compounds at this wavelength (4). This absorption resulted in NO release and consequent formation of free radical species such as $\mathrm{RS}^{\circ}$ (Equation 1) in a pseudo-first-order process (2).

$$
\mathrm{RSNO} \rightarrow \mathrm{RS}^{\bullet}+\mathrm{NO}
$$

Changes in the absorption spectrum of 2 mM GSNO solutions previously saturated with oxygen were monitored as a function of light exposure. Figure 3 shows that after light exposure using 10 laser pulses of $50 \mathrm{~mJ}$ each a decrease in GSNO concentration occurred due to the homolytic fission of the S$\mathrm{N}$ bond (Equation 1).

After homolysis of the S-N bond (Equation 1), other processes can occur such as

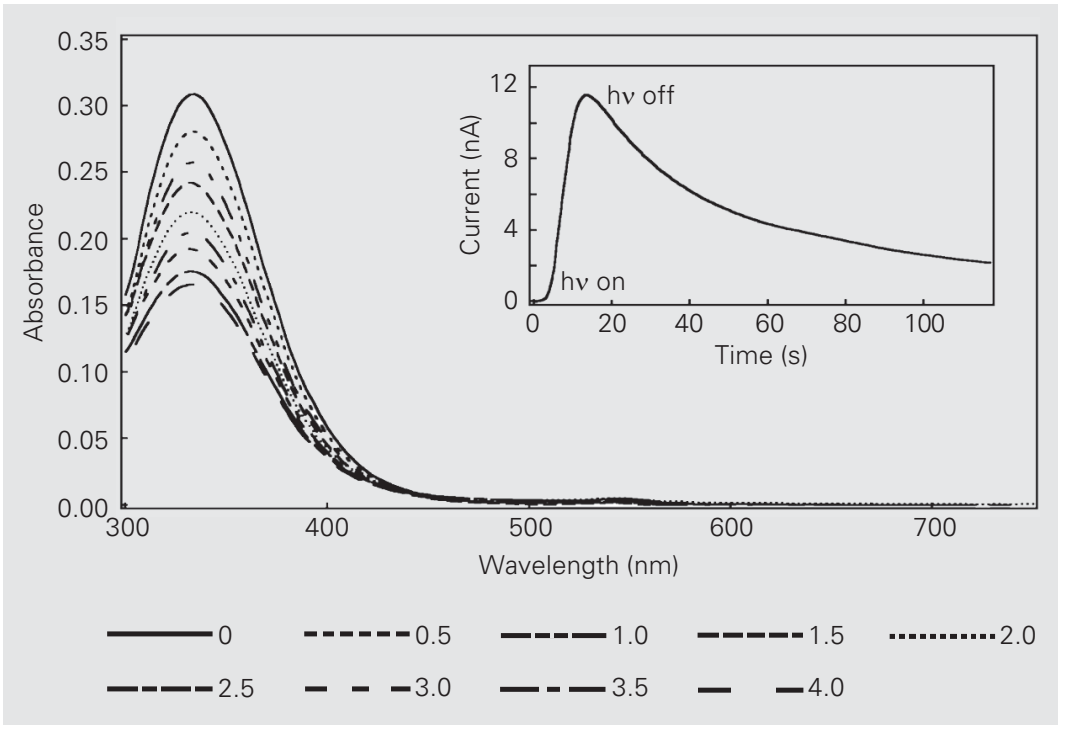

Figure 3. Ground-state absorption spectrum of S-nitroso-glutathione (GSNO; initial concentration $=2.0 \mathrm{mM}$ ) in an air-saturated $\mathrm{PBS} / \mathrm{HCl}$ solution, $\mathrm{pH} 6.4$, showing the decrease in absorption at $355 \mathrm{~nm}$ following irradiation with a total laser energy of $0.5,1.0,1.5,2.0,2.5$, 3.0, 3.5, and $4.0 \mathrm{~J}$. The inset displays the chronoamperogram of nitric oxide released by photolysis of $2 \mathrm{mM}$ GSNO in an aerated $10 \mathrm{mM} \mathrm{PBS} / \mathrm{HCl}$ buffer solution, $\mathrm{pH} 6.4$, after irradiation at $355 \mathrm{~nm}$ with a total laser energy of $0.5 \mathrm{~J}$. reaction of the thiyl radical formed with GSNO to yield GSSG and further NO (Equation 2), or with oxygen to yield the peroxy radical (Equation 3) with a rate constant close to the diffusion process $\left(k=3.0 \times 10^{9}\right.$ $\left.\mathrm{M}^{-1} \mathrm{~S}^{-1}\right)$. The peroxy radical formed reacts with GSNO to yield GSSG and NO (Equation 4) (4). Both processes leading to NO production present rate constants close to the diffusion limit.

$$
\begin{aligned}
& \mathrm{GS}^{\bullet}+\mathrm{GSNO}=\mathrm{GSSG}+\mathrm{NO}\left(k=1.7 \times 10^{9}\right. \\
& \left.\mathrm{M}^{-1} \mathrm{~S}^{-1}\right) \\
& \mathrm{GS}^{\bullet}+\mathrm{O}_{2}=\mathrm{GSOO}^{\bullet} \\
& \mathrm{GSOO}^{\bullet}+\mathrm{GSNO}=\mathrm{GSSG}+\mathrm{NO}+\mathrm{O}_{2}(k=3.8 \\
& \left.\mathrm{x} 10^{8} \mathrm{M}^{-1} \mathrm{~s}^{-1}\right)
\end{aligned}
$$

The RSNO compounds studied showed a slow initial generation of $\mathrm{NO}$ due to thermal decomposition, which was nonsignificant in our experiments. In contrast, NO release was accelerated by direct light excitation (hv on). The inset in Figure 3 shows this behavior for GSNO which, after irradiation with a total laser energy of $0.5 \mathrm{~J}$, showed an NO release of $221 \pm 19 \mathrm{nM}$. When irradiation was stopped ( $h v$ off) an electrochemical signal showing decay of NO started, following a second-order reaction which was most probably due to a relatively slow diffusion process (lifetime of NO $80 \mathrm{~s}$ ) (14).

Another possible explanation for this slow decay of NO release can be due to NO autooxidation induced by molecular oxygen dissolved in solution (15). The reaction with $\mathrm{O}_{2}$ consumes two $\mathrm{NO}$ equivalents and produces two nitrogen dioxide $\left({ }^{\circ} \mathrm{NO}_{2}\right)$ equivalents (Equations 5-7). The radical-radical combination reaction between $\mathrm{NO}_{2}$ and $\mathrm{NO}$ yields an electrophilic nitrosating species known as dinitrogen trioxide $\left(\mathrm{N}_{2} \mathrm{O}_{3}\right)$ (Equation 8). The initial S-nitrosothiol, RSNO, can be regenerated by reaction of thiol nitrosation with $\mathrm{N}_{2} \mathrm{O}_{3}$ (Equation 9) $(5,14,15)$.

$\mathrm{NO}+\mathrm{O}_{2}=\mathrm{ONOO}^{\circ}$

(Eq. 5) 


$$
\begin{aligned}
& \mathrm{ONOO}^{\bullet}+\mathrm{NO}=\mathrm{ONOONO} \\
& \mathrm{ONOONO}=2{ }^{\circ} \mathrm{NO}_{2} \\
& \mathrm{NO}_{2}+\mathrm{NO}=\mathrm{N}_{2} \mathrm{O}_{3}\left(k=1.1 \times 10^{9} \mathrm{M}^{-1} \mathrm{~s}^{-1}\right)
\end{aligned}
$$

(Eq. 8)

$\mathrm{RSH}+\mathrm{N}_{2} \mathrm{O}_{3}=\mathrm{RSNO}+\mathrm{NO}_{2}^{-}+\mathrm{H}^{+}$

Analogous experiments were carried out for $2 \mathrm{mM}$ NacySNO in buffer solutions at $\mathrm{pH}$ 6.4 and 7.4 (data not shown) using laser energy of 0.1 and $0.5 \mathrm{~J}$ and the results showed that NO release from NacySNO followed the same process as described previously for GSNO. The values of NO release obtained in these experiments are displayed in Figure 4, which shows that NO release is dependent on laser energy and $\mathrm{pH}$. When laser energy was increased from 0.1 to $0.5 \mathrm{~J}$, NO release by GSNO and NacySNO was increased about 1.8-fold. The measurements of NO release in more acidic medium ( $\mathrm{pH}$ 6.4) showed higher values than in physiological medium (pH 7.4). We also observed that NO release from NacySNO was higher than from GSNO under the same experimental conditions.

A similar procedure was followed in homogeneous buffer solutions for GSNO and NacySNO for changes in NO release for flash photolysis to NacySNO in liposomes. The results obtained practically showed no difference from those for RSNO in homogenous solution, as illustrated in Figure 4. The chronoamperogram (inset A, Figure 5) indicated that after photolysis was stopped $\mathrm{NO}$ concentration decreased in a second-order reaction in agreement with the mechanism described in Equations 5-9. It can also be observed that the release of NO in liposomal medium was dependent on the laser energy applied. When a higher intensity of irradiation was used in the process of NO generation the result was a higher release of $\mathrm{NO}$ into the system (e.g., NO release from NacySNO liposomes was $176 \pm 17$ and 243 $\pm 0.03 \mathrm{nM}$ for a laser energy of 0.1 and $0.5 \mathrm{~J}$, respectively).

Ground-state absorption experiments for
NacySNO liposome at pH 7.4 (inset B, Figure 5) showed a decrease in the absorption intensity band in the $300-400 \mathrm{~nm}$ region as a consequence of NacySNO decomposition. Another important aspect observed was a

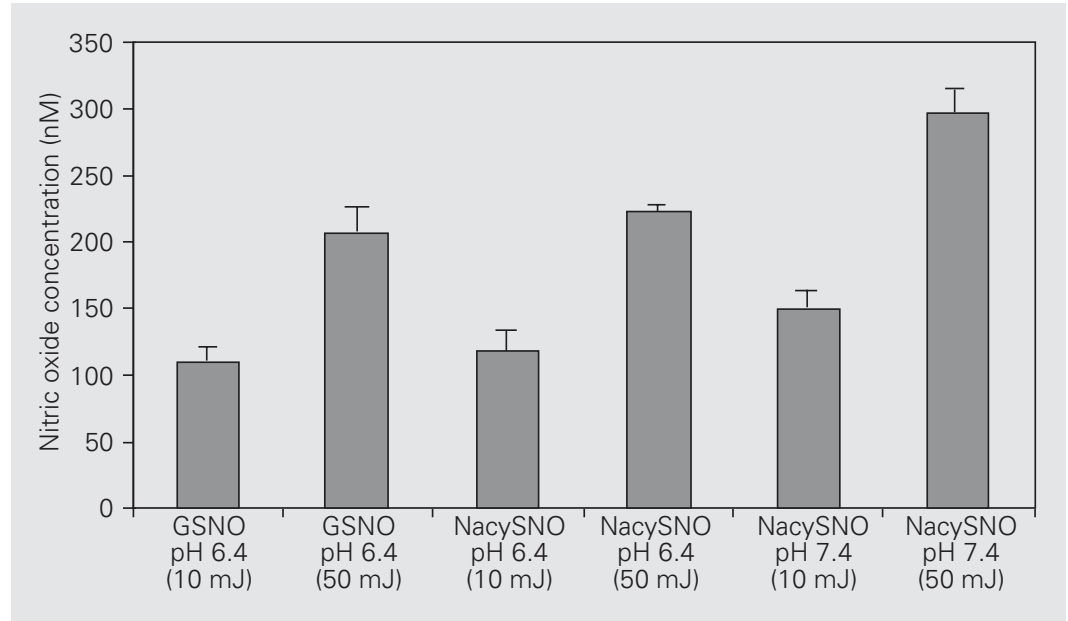

Figure 4. Nitric oxide concentration (nM) for S-nitroso-glutathione (GSNO) and S-nitroso- $N$ acetylcysteine (NacySNO) in PBS/HCl buffer, $\mathrm{pH} 6.4$, and PBS, pH 7.4, after irradiation with a total laser energy of 0.01 and $0.05 \mathrm{~J}$.

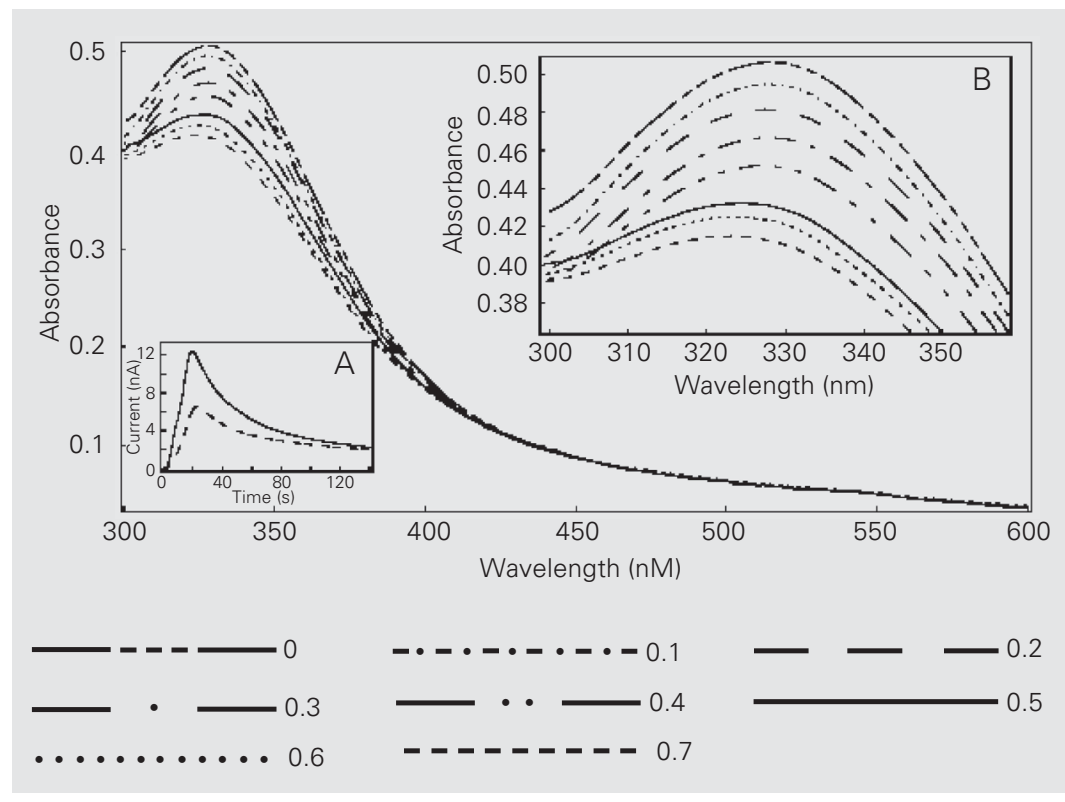

Figure 5. Ground-state absorption spectrum of S-nitroso-N-acetylcysteine (NacySNO; initial concentration $=2.0 \mathrm{mM}$ ) in liposomes showing the decrease in absorption at $355 \mathrm{~nm}$ following irradiation with a total energy of $0.1,0.2,0.3,0.4,0.5,0.6$, and $0.7 \mathrm{~J}$. Inset $A$ displays the chronoamperogram of nitric oxide released by photolysis of $2 \mathrm{mM}$ NacySNO in liposomes using irradiation $(355 \mathrm{~nm}$ ) with 0.1 and $0.5 \mathrm{~J}$. Inset $B$ shows the enlargement of the ground-state absorption band in the spectrum of NacySNO in the $300-360 \mathrm{~nm}$ region. 
band shift centered between 300 and $305 \mathrm{~nm}$ (after application of a laser energy of $0.5 \mathrm{~J}$ ), an indication of peroxynitrite generation (13). The peroxynitrite generation is due to the increased concentration of decomposition products leading to an increase in superoxide concentration, which in turn reacts with NO leading to peroxynitrite formation (Equation 10).

$\mathrm{NO}+\mathrm{O}_{2}{ }^{\cdot-} \rightarrow{ }^{-} \mathrm{OONO}\left(k=4-7 \times 10^{9} \mathrm{M}^{-1} \mathrm{~s}^{-1}\right)$

It was possible to measure NO release in liposomal medium and the NO produced diffused into a hydrophobic medium (phospholipids) and can be detected. This is due to the fact that NO, like $\mathrm{O}_{2}$, is somewhat lipophilic and has 6- to 8-fold higher solubility in nonpolar solvents and lipid membranes compared to water (5). Thus, the rates of NO reactions in hydrophobic environments can be dramatically increased (e.g., with $\mathrm{O}_{2}$ ) compared to reactions in water due to its increased concentration. It has been clearly

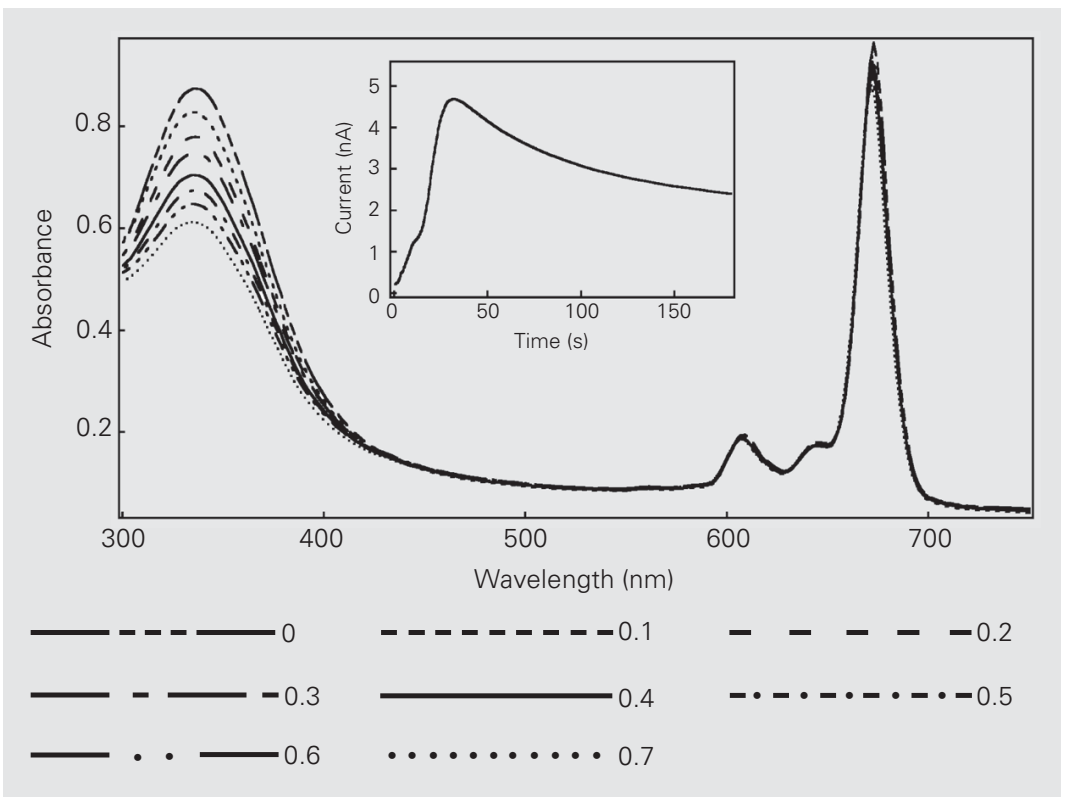

Figure 6. Ground-state absorption spectrum of the S-nitroso- $N$-acetylcysteine-zinc phthalocyanine (NacySNO-ZnPC) complex in liposomes showing the decrease in absorption at 355 $\mathrm{nm}$ following irradiation with a total energy of $0.1,0.2,0.3,0.4,0.5,0.6$, and $0.7 \mathrm{~J}$. The inset displays the chronoamperogram of nitric oxide released by photolysis of $2 \mathrm{mM}$ NacySNO in liposomes using irradiation $(355 \mathrm{~nm}$ ) with a laser energy of $0.5 \mathrm{~J}$. demonstrated that the reaction of $\mathrm{NO}$ with $\mathrm{O}_{2}$ in a hydrophobic phase proceeds 300 times more rapidly than in the aqueous phase because $\mathrm{NO}$ and $\mathrm{O}_{2}$ concentrations are much higher in the former than in the latter. This finding suggests that the auto-oxidation of $\mathrm{NO}$ and the subsequent reactions occur rapidly within the membrane (16).

In our studies we also evaluated the release of NO from $2.0 \mathrm{mM}$ NacySNO in liposomal medium in the presence of $5.0 \mu \mathrm{M}$ $\mathrm{ZnPC}$, a well-known photosensitizer used in photodynamic therapy. Our results (Figure 6) showed that both probes in liposomal medium maintained their spectral profile after photolysis, i.e., the typical absorption bands of phthalocyanines in the visible light region $(600-700 \mathrm{~nm})$, namely the Q band, and the Soret band in the violet or ultraviolet region (300-350 nm), and the typical absorption band of NacySNO in the ultraviolet region (300-350 nm) and visible light region (500-600 nm). Changes in the absorption spectra were observed as a function of light exposure. After flash photolysis, a decrease in NacySNO concentration occurred according to the mechanism described earlier (Equations 1-4).

The presence of $\mathrm{ZnPC}$ induced a decrease of NO release by photochemical decomposition (Figure 6, inset). This behavior can be explained on the basis of a competition process for the energy of flash photolysis $(355 \mathrm{~nm})$, since both sensitizers have absorption bands in this region. The opposite behavior was observed for photosensitizers such as aluminum phthalocyanine tetrasulfonate, hematoporphyrin and Rose Bengal, which show enhanced NO release from donor compounds (6). This behavior can be attributed to the energy transfer process between the triplet state of the photosensitizer (e.g., Rose Bengal $\lambda_{\text {absorption }}=550$ $\mathrm{nm})$ and the triplet of S-nitrosothiols ( $\lambda_{\text {absorption }}$ $=550-600 \mathrm{~nm}$ ) leading to an enhancement of the energy necessary for an efficient homolytic decomposition and to a consequent 
increase of NO release (6).

During the photosensitization of $\mathrm{ZnPC}$ in liposomes, active oxygen species other than singlet oxygen could be generated (16). The use of $\mathrm{ZnPC}$ permits a synergistic action between both sensitizers (ZnPC and RSNO) resulting in the formation of reactive species such as peroxynitrite $\left(\mathrm{ONOO}^{-}\right)$, superoxide anion radical $\left(\mathrm{O}_{2}{ }^{-}\right)$, hydroxyl radical $(\cdot \mathrm{OH})$, nitrogen dioxide $\left(\cdot \mathrm{NO}_{2}\right)$, as well as $\mathrm{NO}$ and singlet oxygen that are extremely important for photodynamic therapy.

Singlet oxygen is produced by a type II mechanism, while a type I mechanism leads to the formation of superoxide anion, as shown in Equations 10-12. After irradiation, there is the formation of triplet $\mathrm{ZnPC}$ (Equation 11), which collides with another ZnPC molecule in the ground state, leading to an electron transfer process (Equation 12). The anion radical produced, $\mathrm{ZnPC}{ }^{\cdot-}$, donates its electron to dioxygen, generating $\mathrm{O}_{2}{ }^{--}$(Equation 13). The process of $\mathrm{ZnPC}$ liposome photosensitization can generate the hydroxyl radical via reduction of hydrogen peroxide (Equations 14 and 15).

$$
\begin{aligned}
& \mathrm{ZnPC}+\mathrm{h} v \rightarrow{ }^{1} \mathrm{ZnPC} \rightarrow{ }^{3} \mathrm{ZnPC} \\
& \left.{ }^{3} \mathrm{ZnPC}+\mathrm{ZnPC} \rightarrow \mathrm{ZnPC}^{\cdot-}+\mathrm{ZnPC}^{\bullet+} \text { (Eq. } 12\right) \\
& \mathrm{ZnPC}^{\cdot-}+\mathrm{O}_{2} \rightarrow \mathrm{ZnPC}^{+}+\mathrm{O}_{2}{ }^{--} \\
& \mathrm{O}_{2}{ }^{\cdot-}+\mathrm{O}_{2}{ }^{\cdot-}+2 \mathrm{H}^{+} \rightarrow \mathrm{H}_{2} \mathrm{O}_{2}+\mathrm{O}_{2} \\
& \mathrm{ZnPC}^{--}+\mathrm{H}_{2} \mathrm{O}_{2} \rightarrow \mathrm{ZnPC}+{ }^{\circ} \mathrm{OH}+\mathrm{OH}^{-}
\end{aligned}
$$

Peroxynitrite, a potent oxidizing agent, is formed by the reaction of superoxide anion radical with $\mathrm{NO}$, an extremely easy process since both have an unpaired electron (Equation 16). The $\mathrm{ONOO}^{-}$, once protonated, rapidly decomposes to $\mathrm{H}^{+}$and $\mathrm{NO}_{3}{ }^{-}$through an intermediate complex owing to the characteristics of both nitrogen dioxide and hydroxyl radical (Equation 17). Peroxynitrite can react with a number of biomolecules, including thiols, amines, lipids and proteins (17). The concentration of $\mathrm{CO}_{2}$ in vivo is high (ca. $1 \mathrm{mM}$ ), and the rate constant for reaction of $\mathrm{CO}_{2}$ with $\mathrm{ONOO}^{-}$is also high (pH-independent $k=3 \times 10^{4} \mathrm{M}^{-1} \mathrm{~s}^{-1}$ ) (Equation 17). Consequently, the rate of reaction of peroxynitrite with $\mathrm{CO}_{2}$ is so fast that most commonly used scavengers would need to be present at very high, near toxic levels in order to compete with peroxynitrite for $\mathrm{CO}_{2}$. The mechanism of the reaction of $\mathrm{CO}_{2}$ with $\mathrm{ONOO}^{-}$produces metastable nitrating, nitrosating, and oxidizing species as intermediates. The role of $\mathrm{CO}_{2}$ is ambiguous. It is postulated that it can serve as a catalyst for $\mathrm{ONOO}^{-}$degradation or can serve to activate $\mathrm{ONOO}^{-}$as a nitrating agent (18).

$\mathrm{HOONO} \rightarrow\left[\mathrm{HO} \cdot+\cdot \mathrm{NO}_{2}\right] \rightarrow \mathrm{NO}_{3}{ }^{-}+\mathrm{H}^{+}$ (Eq. 16)

$-\mathrm{OONO}+\mathrm{CO}_{2} \rightarrow \mathrm{ONOOCOO}^{-}\left(k=3 \times 10^{4}\right.$ $\left.\mathrm{M}^{-1} \mathrm{~s}^{-1}\right)$

The data reported here demonstrate the behavior of NO-donating compounds in solution after flash photolysis under different experimental conditions. Changes in $\mathrm{pH}$, laser energy, NO donor and environment medium were shown to release NO, as illustrated in Figure 7, which shows that NO release from NacySNO after application of a laser energy of $0.5 \mathrm{~J}$ was higher at $\mathrm{pH} 7.4$ than at $\mathrm{pH} 6.4$ (19) and lower in the NacySNO/ZnPC complex.

An important observation reported here

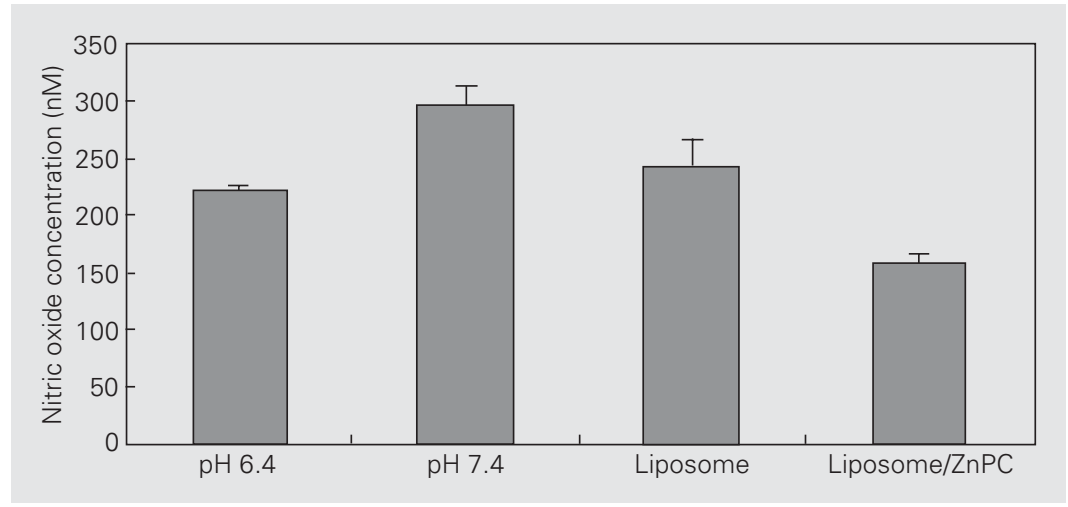

Figure 7. Nitric oxide concentration for S-nitroso- $\mathrm{N}$-acetylcysteine in $\mathrm{PBS} / \mathrm{HCl}$ buffer solution, pH 6.4, and PBS, pH 7.4, in liposomes and in the zinc phthalocyanine (ZnPC)/liposome complex. Data are reported as mean $\pm \mathrm{SD}$ in $\mathrm{nM}$ for five experiments. 
is that incorporating the insoluble photosensitizer ZnPC into liposomal medium together with RSNO does not alter the photophysical properties of the two compounds. This behavior permitted the study of the synergistic action of both active species (NO and $\mathrm{ONOO}^{-}$) produced under photolysis, result- ing in the formation of reactive species which could react with a wide range of biological substrates, and which has been implicated in many pathophysiological conditions, increasing the photodynamic action of the RSNO and $\mathrm{ZnPC}$ complex.

\section{References}

1. Hoog N (2000). Forum: Therapeutic applications of reactive oxygen and nitrogen species in human disease. Free Radical Biology and Medicine, 28: 1478-1486.

2. Williams DLH (1999). The chemistry of S-nitrosothiols. Accounts of Chemistry Research, 32: 869-876.

3. Ceron PIB, Cremonez DC, Bendhack LM \& Tedesco AC (2001). The relaxation induced by s-nitroso-glutathione and s-nitroso-n-acetylcysteine in rat aorta is not related to nitric oxide production. Journal of Pharmacology and Experimental Therapeutics, 298: 1-9.

4. Wood PD, Mutus B \& Redmond RW (1996). The mechanism of photochemical release of nitric oxide from s-nitrosoglutathione. Photochemistry and Photobiology, 64: 518-524.

5. Ignarro LJ (2000). Nitric Oxide: Biology and Pathobiology. Academic Press, San Diego, CA, USA, 41-75 and 895-897.

6. Singh RJ, Hogg N, Joseph J \& Kalyanaraman B (1995). Photosensitized decomposition of S-nitrosothiols and 2-methyl-2-nitrosopropane. Possible use for site-directed nitric oxide production. FEBS Letters, 360: 47-51.

7. Wink DA, Vodovotz $Y$, Cook JA, Krishna MC, Kim S, Coffin D, Degraff W, Delluca AM, Liebmann J \& Mitchell JB (1998). Review: The role of the nitric oxide chemistry in cancer treatment. Biochemistry, 63: 23-37.

8. Maree MD \& Nyokong T (2001). Effect of oligomerization on the photochemical properties of silicon octaphenoxyphthalocyanine. Journal of Photochemistry and Photobiology. A: Chemistry, 142: 3946.

9. Hadjur $\mathrm{C}$, Wagnières $\mathrm{G}$, Ihringer $\mathrm{F}$, Monnier $\mathrm{PH}$ \& van den Bergh $\mathrm{H}$ (1997). Production of the free radicals $\mathrm{O}_{2}{ }^{\bullet-}$ and $\bullet \mathrm{OH}$ by irradiation of the photosensitizer zinc (II) phthalocyanine. Photochemistry and Photobiology B, 38: 196-202.

10. Kassab K, Fabris C, Defilippis MP, Dei D, Fantetti L, Roncucci G, Reddi E \& Jori G (2000). Skin-photosensitizing properties of Zn(II)2(3),9(10), 16(17),23(24)-tetrakis-(4-oxy-N-ethylpiperidinyl) phthalocyanine topically administered to mice. Journal of Photochemistry and Photobiology. B: Biology, 55: 128-137.

11. Kremer $\mathrm{JMH}$, von der Esker MWJ, Pathmamanoharan $\mathrm{C}$ \& Wirsma PH (1977). Vesicles of variable diameter prepared by a modified injection method. Biochemistry, 16: 3932-3955.

12. ISO-NO \& ISO-NO Mark II (1996). Isolated Nitric Oxide Meters and Sensors. Instruction Manual. World Precision Instrument, Inc., Sarasota, FL, USA.

13. Wang PG, Xian M, Tang X, Wu X, Wen Z, Cai T \& Janczuk AJ (2002). Nitric oxide donors: chemical activities and biological applications. Chemical Reviews, 102: 1091-1134.

14. Zhelyaskov VR, Gee KR \& Godwin DW (1998). Control of NO concentration in solutions of nitrosothiol compounds by light. Journal of Photochemistry and Photobiology, 67: 282-288.

15. Oliveira MG, Shishido SM, Seabra AB \& Morgon NH (2002). Thermal stability of primary $S$-nitrosothiols: roles of autocatalysis and structural effects on the rate of nitric oxide release. Journal of Physical Chemistry A, 106: 8963-8970.

16. Ford PC, Bourassa J, Miranda K, Lee B, Lorkovic I, Boggs S, Kudo S \& Laverman $L$ (1998). Photochemistry of metal nitrosyl complexes. Delivery of nitric oxide to biological targets. Coordination Chemistry Reviews, 171: 185-202.

17. Nagano T \& Yoshimura T (2002). Bioimaging of nitric oxide. Chemical Reviews, 102: 1235-1269.

18. Augusto O, Bonini MG, Amanso AM, Linares E, Santos CCX \& Menezes SL (2002). Nitrogen dioxide and carbonate radical anion: two emerging radicals in biology. Free Radical Biology and Medicine, 32: 841-859.

19. Ignarro LJ, Lippton H, Edwards JC, Baricos WH, Hyman AL, Kadowitz PJ \& Gruetter SPA (1981). Mechanism of vascular smooth muscle relaxation by organic nitrates, nitrites, nitroprusside and nitric oxide: evidence for involvements of S-nitrosothiols as active intermediates. Journal of Pharmacology and Experimental Therapeutics, 218: 739-749. 